\title{
An Introduction to Food Cooperatives in the Bekaa Valley, Lebanon: Territorial Actors and Potential Levers to Local Development Through Culinary Heritage
}

\author{
Rita Jalkh ${ }^{1,2}$ (D) Marc Dedeire ${ }^{1} \cdot$ Melanie Requier Desjardins $^{2}$
}

Accepted: 8 September 2020 / Published online: 19 September 2020

(C) Springer Nature Switzerland AG 2020

\begin{abstract}
Economic development approaches are increasingly entailing local geographic scales and encouraging the mobilization and organization of territorial actors given local conditions and resources. Lebanon is a country facing frequent uncertainty with recent economic and social difficulties. Its popular cuisine may play a key role in its development and that of its rural space. In fact, that cuisine incorporates a traditional cultural practice called "Mouneh" which consists of preserved pantry foods, historically used to ensure household nutrition. Today, rural food cooperatives are engaging in that practice using agricultural produce from local farmers and are employing women. Despite strong internal and external challenges, they remain attractive actors as their principles of collective benefit, participation and democracy form a strong link with sustainable development goals. This study transversally analyzes the status of food cooperatives in a major agricultural region in Lebanon, the Bekaa valley. Findings mainly quantified size and production and provided a mapped representation of the spatial dependencies on local farmers versus urban markets for trade. With $75 \%$ women members and firm reputation in authenticity, food cooperatives in the Bekaa specifically and Lebanon generally are also extensively supported by donors but are being labeled as donor-dependent. Yet, cooperatives are localized in a largely agricultural territory with sufficient evidence of differentiation that could potentially be valorized. Hence, with optimal framing, regulation and networking of cooperatives, one can assume a protection of culinary heritage is possible with scalable contribution to food security and needed local development given major recent setbacks.
\end{abstract}

Keywords Traditional foods · Cooperatives $\cdot$ Lebanon $\cdot$ Bekaa valley $\cdot$ Sustainable development goals

Rita Jalkh

rita.jalkh@etu.univ-montp3.fr; rijalkh@iamm.fr

Extended author information available on the last page of the article 


\section{Introduction}

The importance of focusing on local micro-economies has been increasingly the subject of scientific discourse (Stöhr 1980; Quan and Nelson 2005; Petrick 2011). In a world governed by international commerce and global economies, favoring "the local" is being encouraged to attain development strategies able to mitigate spatial imbalances, distribution of wealth and the inclusion of localities usually considered as marginalized and mainly rural (Torre and Wallet 2014). Cooperatives are local in nature and the majority of their activities are practiced at the local scale rather than national or regional. They are considered vectors of social and gender inclusion, creators of employment and enhancers of livelihoods operating under democratic governance, participatory approaches and respecting cooperative principles (Smith 2014). This is how cooperatives appear as typical territorial actors whose characteristics make an attractive focus for local development strategies especially those under the UN 2030 agenda's Sustainable Development Goals (SDGs). In Lebanon, cooperatives remain less successful than other international achievements. Yet, in a country facing chronic uncertainty, food import dependency, post-war reconstruction attempts and consecutively emerging crises, cooperatives are becoming increasingly recognized for their potential collective benefit. A study by the management consultancy firm McKinsey \& Company (2018) reported the agricultural sector as one of 6 "productive" sectors for development in Lebanon. In addition to recommending support to agricultural cooperatives, the report advised focusing on the local food sector. Food plays a major role in Lebanon and the Lebanese cuisine is popular on a global scale. Traditional pantry foods, referred to as "mouneh", in fact are an essential ingredient in the Lebanese gastronomy. Historically, the manufacturing of mouneh foods occurred through the preservation of seasonal produce and their shelf-stable storage at the level of households to secure nutrition and food security needs for the winter season (Massaad 2017). Such preservation techniques included drying, pickling and fermentation. Today, changing lifestyles, economic constraints, technology and rural exodus have limited domestic production of traditional mouneh foods. However, small producers such as cooperatives are increasingly participating in the production of artisanal mouneh, despite their poor positioning in the market compared to similar industrial counterparts. Such cooperatives usually follow artisanal practices and mainly employ women (ILO 2018). Their socio-economic and gender properties have also attracted external support from donors for development projects. In that regards, this paper aims to provide a transversal introduction to the spatial linkage and status of main operations of cooperatives that manufacture traditional Lebanese foods in the Bekaa valley. We attempt to understand if culinary heritage could be valorized to favor links between different players starting with upstream cooperatives, to women in food processing cooperatives and downstream to consumers. This work sheds light on traditional food products and their cooperative producers in order to pave for future research relating to their potential efficient organization and facilitating provision and accessibility to such foods. This paper is based on a 3-tier approach considering traditional mouneh foods as the cultural resource, the Bekaa valley as the territory of focus and food cooperatives as the main players. The Bekaa valley was selected as it is a fertile stretch of land characterized by significant agricultural activities with a central role on the country's primary sector. Additionally, the valley's locality and distinct geoclimatic conditions make it a suitable study area. The study becomes more relevant given the recent three major crises that hit the country starting with the economic setback in October 2019 compounded by the novel COVID-19 pandemic and finally the destructive Beirut port explosion in August 2020. These recent crises greatly restricted access 
to liquidity, diminished the already weakened productive sectors, and affected importations which raised fear of national food insecurity. Under such context, the question of food security and sustainability could therefore quickly become the newer essential form of the country's preoccupation.

\section{Geographically Rescaling Development}

In the words of Stiglitz (2007) "Globalization had succeeded in unifying people from around the world-against globalization". Without undermining its role in shaping global economies, a newer and smaller scale of economic activities has however emerged. It relates to the local, and more specifically territorial, levels of space and their place-based actors being progressively recognized as economic grounds capable of reaching their own development routes. A strong belief is being based on the activation of bottom-up development originating from internal forces of specific territories (Lamine et al. 2012). In his article, Erik Swyngedouw (2004) described the process as "Glocalization" which refers to the simultaneous downscaling of institutional arrangements and economic activities to more local levels. Hence, rather than relying solely on top-down strategies directed by the state and authorities, smaller scale geographically distinct areas are being looked at as fertile spaces for the building of economic activities. The latter is usually preferred when based on the identification, capitalization and sustainable management of differentiation factors - endogenous resources - within the local context, by the local players. The so-called "markers" are inclusive of factors not only relevant to the primary agricultural and food sector, but have been noted to incorporate languages and dialects, folklore, arts and drama, archeological sites and landscape components (Swyngedouw 2004) under an overall cultural approach equivalent to a territorial identity. Hence the origin of "culture economy approach to development" (Ray 2001) which is thought of as the localization of economic control within a certain territory, valorizing its cultural resources within its local network of actors. This is how a neo-endogenous approach to development can be considered as the creation of suitable conditions which stimulate local initiatives within general directed guidelines; a manifestation both the "from above" and "from within" (Ray 2001). Despite having much more concrete theoretical frameworks and implementations based on developed economies and especially for the benefit of their rural spaces, recent theoretical and case-study literature highlight the possibility of transferring such approaches to developing countries (Galdeano-Gómez et al. 2011; Delgado-Serrano et al. 2015; Bosworth et al. 2016). Not without its own set of challenges and needed adaptation, Pecqueur (2013) for example acknowledges that the emergence of territorial development as a potential solution to the changes in the global economy applies to industrialized economies as well as developing countries. Yet, he clearly states how each local context requires a holistic approach of public action, which in turn raises itself wider than the simple, yet necessary, capability of the state and regulatory policies, but for the needed mobilization, structure and coordination amongst actors.

\section{Cooperatives and the Sustainable Development Goals (SDGs)}

It is estimated that nearly 1 in 6 people on the planet are on average directly or indirectly linked to cooperatives (Grace 2014). Cooperatives are a social model of businesses which differ from profit-driven companies by focusing on collective benefit, participation, solidarity and 
democracy. The role of cooperatives as contributors to the SDGs agenda has been highlighted on different levels. A cooperative is firstly defined as "an autonomous association of persons united voluntarily to meet their common economic, social and cultural needs and aspirations through a jointly owned and democratically controlled enterprises."1 (Smith 2014). Coupled with the definition, the 7 cooperative principles are probably the first indication to the values of such enterprises. Although different experiences suggest their respecting to a various extent, they fall well in line with the SDGs. These include (1) voluntary and open membership, (2) democratic member control, (3) members' economic participation, (4) autonomy and independence, (5) education, training and information, (6) cooperation among cooperatives and (7) concern for community (Smith 2014). In fact, a report by The International Labour Organization (ILO) exclusively analyzed the link between cooperatives and the SDGs even prior to the announcement of the specific goals, targets and indicators by late 2015 (Wanyama 2016). The report stressed how "cooperatives are well-placed to contribute to sustainable development's triple bottom line of economic, social and environmental objectives plus the governance agenda...". Such strong statements are supported by figures which reflect the extent and recognized achievements of cooperatives globally. An extensive database on cooperatives created for the United Nations Secretariat (Grace 2014) reported the existence of 2.6 million cooperatives of which 770,000 employ 12.6 million individuals and generate US\$ 3 Trillion in annual revenue. Highest contributions of cooperatives to national economies were noted to reach $20 \%$ of New Zealand's Gross Domestic Product (GDP), 18\% in the Netherlands and France and $14 \%$ in Finland.

Besides their grand achievements in developed countries, cooperatives have also been recognized by the same ILO report (Wanyama 2016) for their impressive input in developing economies within different SDGs headlines. Relevant examples include successful initiatives from Tanzania, Egypt and Ethiopia where agricultural cooperatives improved marketing, sales, income generation and the livelihoods of millions of farmers, thus contributing to Goal 1 of poverty reduction. Other figures from East African countries and Arab states highlight cooperatives' input under Goal 2 of gender equality mainly by enhancing women's economic participation and social inclusion. A strong and apparent link was also presented between cooperatives with Goals 5 and 8 relating to food security and good nutrition, and job creation and equitable growth; interestingly adding an element of preserving indigenous food crops. Cooperatives in developing economies have also been praised for enhancing access to - and management of clean water (Goal 6) as in Bolivia and Latin America; provision of sustainable and renewable energy (Goal 7) to rural populations as in Bangladesh's rural electrification cooperatives; and sustainable management of natural resources (Goal 9) with diverse experiences from Indonesia, Columbia, Philippines and others, relating to waste collection, sanitation and sustainable use of resources. Moreover, a positive impact of cooperatives has also been reported in conflict-affected countries. Such is the case in Nepal for example where different types of cooperatives reported positive growth during the insurgency period of 1997 to 2007 (Bagchi and Gautam 2019) especially in rural settings. Impressive growth was attained specifically by microcredit cooperatives owed to their provision of financial means to rural populations when banks failed. In Africa, a long-term strategy for cooperatives is being encouraged as a suitable path to mitigate the root causes of conflict. These include peacebuilding and development of post-crisis economies for countries as

\footnotetext{
${ }^{1}$ This definition was initiated by the International Cooperative Alliance, found at https://www.ica. coop/en/cooperatives/cooperative-identity, and later adopted by the International Labour Organization (ILO) in its Recommendation No 193.
} 
Burundi and Liberia (Okem 2016). Such suggestions were further emphasized following successful applications in Rwanda and Kenya where cooperatives supported thousands of farmers in financing their productions. For conflict and post-conflict Arab states, and even with a set of barriers and limitations, cooperatives stepped up mainly in their inclusion and empowerment of women. In Palestine, the political mobilization of women during the first Intifada protests was greatly linked to cooperatives although sources mention they later became marginalized after the Oslo Accords (Esim and Omeira 2009). Even in Lebanon, food cooperatives were reported to engage in the rebuilding of societies in regions that were significantly affected during the 2006 war (Esim and Omeira 2009). More relevantly, they were acclaimed to revive traditional foods on the verge of extinction.

\section{Lebanon, Cooperatives and the Bekaa Valley}

Lebanon is a small Mediterranean country whose need for development stretches over various aspects as economic, institutional and social. In brief, its economic performance confers a struggling post-war reconstruction with spending and trade deficit equivalent to $\$ 3.67$ billion and $\$ 16.7$ billion in 2017 respectively (El Tabch 2018) with a climbing budget deficit-to-GDP ratio reaching the 3rd highest worldwide at around 153\% (Youssef 2020). Previous poverty estimates by the Lebanese Ministry of Social Affairs (MoSA) and the United Nations Development Programme (UNDP) state almost $30 \%$ of Lebanese population, equivalent to 1.5 million individuals, living under $\$ 4.00 /$ person/day with highest concentrations observed in the Bekaa valley (El Laithy et al. 2008). These numbers are however expected to have considerably increased following three consecutive crises that hit Lebanon. These started with a grave hyperinflation since October 2019 dictating a loss of $60 \%$ of the local currency's value at best. Aggravated by the COVID-19 pandemic, a general mobilization was issued in Lebanon since March 2020 and is still ongoing as of August 2020. These conditions created multilayered complications at the economic, social and health fronts only to climax with a massive explosion at Beirut's port on August 4 2020, destroying vast parts of the city and displacing hundreds of thousands. With price hikes, decreased income, and unemployment, poverty is feared to touch $45 \%$ of the Lebanese population. Even farmers were estimated to be losing $70 \%$ of their earnings following a $40 \%$ drop in the agro-industry sector (UNOCHA 2020). The presence of Syrian refugees adds more stress to the already fragile state. This is especially true for the Bekaa where the highest concentration of refugees was recorded at $37.6 \%$ of over 950,000 refugees residing in Lebanon in 2018 (The Government of Lebanon and the United Nations 2019), compared to a population of slightly over 6 million. Due to the above concoction coupled with Lebanon's import dependency of up to $80 \%$ of its food needs (ESCWA 2016) along with the destruction of $80 \%$ of grain reserves during the port explosion, national fear of food insecurity is reaching a critical level. Prior to the exceptional crises, the agricultural sector has been widely acknowledged for its economic importance at a national scale despite its low contribution to the national GDP, reported at about 4\% in 2018 (World Bank 2018). The World Bank acknowledges the compounded importance when coupling agriculture with inputs of the food production sector. Together, with their indirect contributions, the agro-food sectors increase the contribution to Lebanon's national GDP from $4 \%$ to 25-30\% and are thus able to support growth as they combine up to one-quarter to one-third of the economy. In fact, the local Investment Development Authority of Lebanon (IDAL) state that the sector employs a significant number of personnel accounting for $25 \%$ of the industrial 
sector workforce (IDAL 2020). In rural settings, the agricultural sector is stated as a primary source of income with local GDP contribution increasing up to $80 \%$ as stated by Food and Agriculture Organization of the United Nations (FAO)'s country brief. ${ }^{2}$ These include areas as North and South Lebanon as well as the Bekaa which yet reinforces the sector's significance.

Cooperatives in Lebanon existed since 1964 with the introduction of the Cooperative Association Law which defined cooperatives under Decree No. 17199 as “... each association consisting of persons with unlimited capital and not aiming for profit ... and whose aim is to improve the economic and social status of its members by concerting their efforts in accordance with the principles of public cooperation." (translated from Arabic). Cooperatives faced an unstable route during their history being mainly dependent on state capacity. They were first supported by the state following the introduction of the Decree but later faced great neglect as a result of the civil war between 1975 and 1990 only to later re-emerge thanks to donor funds (Esim and Omeira 2009). A "boom" in the number of cooperatives was even registered after the year 2000 following the end of the occupation in South Lebanon (ILO 2018). Cooperatives have been - and still are - an attractive focus for rural development due to their ability to help meet development objectives of donors and their bridging with the local context. However, different sources including McKinsey \& Company (2018) reported that cooperatives generally have a weak role in Lebanon. Out of the 1,238 total existing cooperatives in the country, only 1 in 3 is active, knowing that almost half of the latter are agricultural cooperatives in which only $4.5 \%$ of Lebanese farmers are members (Lebanese Ministry of Agriculture 2014). Due to their high proportion, agricultural cooperatives are mentioned to have the potential to support local farmers by enabling and expanding their access to markets but are however not currently successful in doing so (ILO 2018). Out of the numerous recommendations, specific propositions entailed focusing on food-processing activities that utilize local agricultural products. The ILO (2018) states that 125 registered women cooperatives exist and work mostly in the processing of traditional pantry foods such as dry products, distillates, jams, pickles and preserves. This type of cooperatives usually differs in configuration by centralizing production in an atelier-like workshop rather than the mass collection of products cultivated separately by a group of farmers, as in the case of agricultural cooperatives. Such food processing cooperatives are also noted by the ILO (2018) to have varying infrastructures in terms of equipment, technological advancements and quality of production. Even though few and rare descriptions of this type of women food cooperatives exist, much-needed fundamental information is still needed.

These cooperatives' main output, traditional mouneh foods, can be considered as a familiar cultural concept in the Lebanese context, despite entering in no apparent state definition or strategy. A few available literature reflect the correlation of mouneh foods with heritage. A report by the MoET (Abu Ghyda 2007) for example described mouneh as "... according to the consumers, a product linked to the region of production, to the terroir where the product is produced and to the landscape which surrounds the place... The concept of "Mouneh" arised many centuries ago, when the producers worked on preserving their products of origin in order to consume them during the wintertime". A PhD study by Claude Challita (2010) also noted the common use of the word "Baladi" being interchangeable with the word "traditional" in Lebanon and links with village life. A book holding the same name as the tradition, "Mouneh", even describes the diverse linguistic relevance of the word (Massaad 2017). "Mouneh" originates from the Arabic word "Mana" which means "to store", hence designating the storage room for such products as "Oudit Al-mouneh", translating to "The mouneh

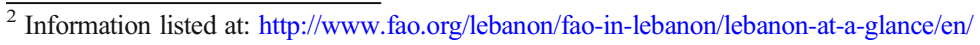


room”. Nevertheless, this range of traditional products lacks any national recognition by means of official specifications or built valorization system. This fact was suspected to affect consumer perception, and consequently sustainable consumption, due to an inability in clearly identifying origin and quality (Zurayk and Abu Ghyda 2009). This could be a main reason why mouneh foods were seen to require differentiation from other similar but industrial products. In her study, Abou-Habib (et al. 2013a) described small-scale women companies using markers as "homemade mouneh" to distinguish their products from those similar but mass-produced. This was adopted since the latter versions did not follow traditional practices or have used additives in their ingredients. The study however recommended placing more focus on gender differentiation by advertising the support to women producers rather than the product themselves, considering that products with similar features are available in the market.

When discussing food cooperatives, the link with the surrounding agricultural atmosphere is pivotal. The Bekaa valley is a natural inland plane dividing Lebanon's two mountain ranges, the Mount Lebanon range on its West and the Anti-Lebanon range on its East. The valley stretches over $4,000 \mathrm{~km}^{2}$ (Bou-Antoun 2014) covering $38 \%$ of the country's surface area and is a main agricultural producing region. The valley comprises of two administrative zones called the Bekaa governorate (not to be confused with the Bekaa valley) and the BaalbeckHermel governorate. The importance of its agricultural setting can be strongly linked to the valley's somewhat enclosed geographic location, diverse geoclimatic conditions and fertile soil which "rarely can be found in comparable areas" (Darwish 2013). The longitudinal stretch of mountains restricts levels of precipitation and humidity from the Mediterranean Sea and in turn characterize the valley with a variety of microclimates owed to its diverse topography (Lateef 2007). According to IDAL's regional descriptions, ${ }^{3}$ the Bekaa valley holds the main surface dedicated for the production of cereals and pulses (57\%), vegetables $(57 \%)$, fruit trees $(36 \%)$, and livestock as sheep (38\%), goats $(29 \%)$, cattle $(26 \%)$ and dairy (44\%). As for its set of cooperatives, the Bekaa valley is reported to host $23 \%$ of all registered cooperatives in Lebanon (ILO 2018). Yet, that percentage is not equally divided amongst its administrative divisions with the Bekaa governorate registering only $7 \%$ of cooperatives although being a territory with sizeable agricultural properties and important intensive agriculture. Specific information on food cooperatives in the Bekaa valley is not elaborated, knowing that reports are found to focus mostly on agricultural cooperatives across the country rather than as a factor of their geographic locality or production activities. It is also important to mention the underdeveloped foundation of data in Lebanon which complicates accessibility, transparency and accuracy of reliable figures. Some limitations faced during the realization of the study included unclear division of cooperatives in official lists per sectoral activities thus difficulties in properly identifying food processing cooperatives. Outdated lists also meant the listing of inactive or informal cooperatives which have in fact ceased production or have been dissolved. Other limits include unclear geographic borders in certain municipalities and internal factors related to the capacities of cooperatives in recordkeeping and documentation.

\section{Methodology}

In order to overcome the overall challenges, the study relied on a qualitative and semiquantitative approach based on the collection of scientific publications, official state

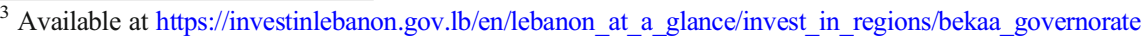


documents and donor reports for literature review and comparative purposes. The methodological approach (Fig. 1) was based on three main steps which, first, aimed to identify the total number of food processing cooperatives in the Bekaa valley, their active production of traditional foods and their location. For that reason, an official list of cooperatives was acquired from the Directorate General of Cooperatives of the Lebanese Ministry of Agriculture (MoA). The list was next refined through phone contact with each of the registered cooperative listed under the desired food processing category. This contact was performed to reduce errors

\section{Methodological Approach}

Step 1

Understanding the spatio-

temporal logic of cooperatives

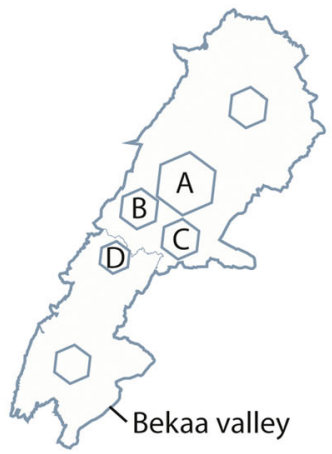

Step 2

Understanding the spatiotemporal logic of actors

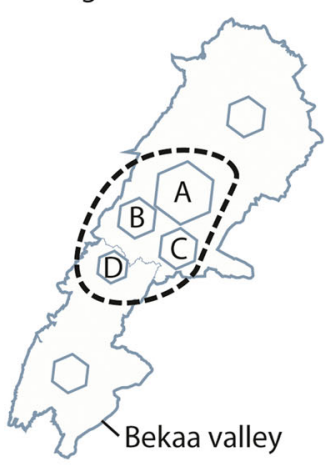

Step 3

Characterization of surveyed cooperatives

Understanding dynamics of local production and potential contribution
Analysis of decrees and statutes of cooperatives in Lebanon

Identification of cooperatives within the Bekaa valley according to official sources

Identification of a network of 40 food-processing cooperatives by reconciling field knowledge and validation through phone contact

Geolocalization of the cooperative network in the Bekaa valley
Structure of the survey in 4 themes:

- Structure of cooperatives

- External support for beneficiary cooperatives

- Research into labeling of mouneh products

- Raw material supply and urban vs rural turnover

Fig. 1 Methodological approach followed during the execution of the study. Source: Jalkh R., 2020, ART-DEV, UM3

Descriptive statistical analysis of the network of 40 cooperatives

Crossing with field knowledge 
related to the official list, and was thus needed to verify the cooperatives' manufacturing of the intended traditional food products, to ensure their active status at the time of the study and finally to compile the total number of said operational food cooperatives in the territory. Forty (40) cooperatives were accordingly identified as the active network of food cooperatives across the Bekaa valley.

The second and third steps of the methodology relied on collecting and analyzing desired information from the entire network of identified cooperatives. A structured questionnaire was therefore developed, out of which a set of questions are extracted and mobilized specifically for the purpose of this article, with the complete questionnaire being part of a larger work undertaken by a $\mathrm{PhD}$ study. This step was considered important to first provide a general introduction of the operations of these cooperatives, upon which broader results could be consolidated with an ensemble of more advanced data treatment. These extracts cover information relating to (1) the structure of cooperatives (number, age and gender of members, production types and volume... etc.), (2) extent of donor support (frequency and type of received support), (3) spatial linkages of main operations (source of raw material supply, source of turnover, means of transportation, marketing channels...etc.) and (4) labeling conformity. To elaborate on these spatial linkages, focus was given on the supply of raw material and major sources of sales turnover in order to describe rural and urban significance. For the labeling component, copies of labels used by each cooperative were collected when available and their compliance was assessed based on European standards compiled by the Ministry of Economy and Trade (2008) through its QUALEB Quality Programme. This was realized by constructing a 10-grade scoring checklist in which the main headlines of the standard were listed. Labels were observed for the presence or absence of each type of information, upon which a score was added for each available information. Data collection was performed between August and December 2019 and took place by way of in-person interviews with directors or decision-makers of cooperatives. Survey questionnaires were filled by hand with no video or voice recording. Interviews commenced only after acquiring the verbal consent of interviewees following a proper description of the meeting's purpose and intended use of information. Anonymity of interviewees and corresponding cooperatives was ensured by assigning a numeric code for each completed questionnaire and its later use during data entry and analysis. All original hard copies of questionnaires were stored after the digital entry of data and were kept private. Interviews were successfully realized with the entirety of the identified network of 40 cooperatives and achieved a full response rate. In summary, data analysis followed a transversal inspection and descriptive statistics of the mobilized survey input in an attempt to provide this general overview. This article can therefore be considered as a benchmark and first understanding of food cooperatives' current operations and status in the Bekaa valley upon which further research can be built. Mapping was conducted using PhilCarto V.6.07-2018 and refined using Adobe Illustrator CC 19.0.0-2015.

\section{Results and Discussion}

Results show that the 40 interviewed food cooperatives, representing the entirety of registered food processing cooperatives in the Bekaa valley, are mostly small in size in both number of members and production quantities. On average, this type of cooperatives includes less than 20 
members whereas the double is usually registered with agricultural cooperatives (ILO 2018). Only 18 cooperative members of the almost 700 in total were less than 30 years of age whereas almost $60 \%$ of all members were over 40 . Similar concerns of an aging farming population and decreasing participation of youth in the agro-food sector were also recently voiced by others as Chalak (et al. 2017) and ILO (2018). Comparable figures to those of ILO (2018) are also recorded by this study showing only $27 \%$ of members aged between 30 and 40 . Additional results on member gender profiles show that these food cooperatives are comprised mostly of women but only half of whom are active in the production process. The engagement of women is highly evident in food cooperatives unlike their low rates of membership in agricultural cooperatives, a fact similarly highlighted by donor reports (ILO 2018; UNDP 2020). Interestingly, 12 cooperatives (30\%) comprised of women-only members and only $12(30 \%)$ reported having less than $70 \%$ women members. These figures reflect an impressive participation of women in leading roles in food cooperative movement unlike other sectors in the country. A report by UNDP (2020) mentions a low participation of women in the general Lebanese labor market with only $4 \%$ of top management roles compared to 5\% in the MENA region and $19 \%$ worldwide. This is further reflected in Lebanon ranking 145 of 153 in the 2020 Global Gender Gap index (World Economic Forum 2020). For the agriculture and food sectors, the same UNDP report mentions an estimated $35 \%$ of women participating in the labor force, remaining stable and consistent with figures reported back in 1970 (Dixon 1982). However, migrant men and women workers from the neighboring Syria are highly integrated, officially and mostly unofficially, in Lebanon's agriculture activities with numbers estimated between 200,000 and 1,000,000 workers (Habib and Fathallah 2012). Although accurate statistics remain unclear, the above UNDP report states that women have shown stronger participation in cultivation, harvesting and packaging whereas their role greatly diminishes when it comes to marketing of fresh produce (UNDP 2020). Contrariwise, it states that women in food processing cooperatives overcome these barriers and are exceptionally seen to take charge of the marketing of their processed foods, a fact also reflected in this study's results as detailed throughout this passage.

In terms of production, results show that the food cooperatives' total annual volume varied between 1 and 7 tons on a seasonal basis for over half of cooperatives. Such low figures were however noted to represent only market-driven quantities which are produced on demand and do not represent the cooperatives' full capacity, thus highlighting a scale-up potential. Yet, $23 \%$ of interviewed cooperatives reported producing over 7 tons and a maximum of 15 tons. Most interviewed food cooperatives produce an array of traditional foods most of which are based on fruits, vegetables, herbs and dairy. These include but are not limited to products such as jams, pickles, preserves, dried fruits, herb mixes and traditional dairy products. Only a few, $20 \%$, were found to specialize in particular products rather than an ensemble. This lack of specificity could be due to the availability of various cultivations across the Bekaa valley which places cooperatives at proximity to a wide range of raw material from which they would prefer to diversity and adapt rather than fix production. Yet, it was noticed that 14 of those cooperatives (35\%) listed a typical mouneh product called Kishk as one of their top 3 productions. Kishk is a form of dried powder made from a mix of yogurt and parboiled wheat called burgul. An extract from a book a called "From "Akkar to "Amel" by Zurayk and Rahman (2008) showcases not only the cultural significance of the product but emphasizes the effects of geographic origin and social specificities in the Bekaa valley on its quality. Kishk is reported to have existed in Lebanon, Syria and Palestine since the tenth century, known as Kishk Chami; referring to the historical name of that area "Bilad Al Cham". Lebanon's kishk 
is made exclusively from wheat, since other countries also use barley, and goat milk is preferred as a "local specialty in the Bekaa valley due to its strong pungent taste". Inter alia, the two major ingredients to be considered are wheat and goat milk. Salamouni wheat (Triticum aestivum L. var. Salamouni) is a native race originating from the Bekaa and its cultivation is still centered in the valley after estimating to date back to 5,000 year ago (Pomeranz 1989). This variety is preferred in the territory "because in the opinion of local farmers (...) it is the best wheat for burghul and kishk production" (Zurayk and Rahman 2008). Rearing of small ruminants has also been historically promoted in the Bekaa valley especially the Anti-Lebanon mountain range due to dry and unproductive conditions. Their specific grazing routes shift between winter and summer from the Bekaa plane up to higher altitudes or the coast which brings evidence of further added characteristics. Finally, one should suspect that the local knowhow and diverse geoclimatic conditions could also interfere in the production and drying of kishk in the valley. It is attractive to demonstrate kishk as a pilot of the Bekaa valley's culinary heritage since it was specifically mentioned by the Ministry of Economy and Trade (MoET) as one of the products with potential eligibility for geographic indication label in the Baalbeck region of the Bekaa valley (Abu Ghyda 2007). Interestingly, this study's results show that all except 2 of the network's food cooperatives with major kishk production are indeed located in the Baalbeck-Hermel governorate in the northern segment of the valley.

These food producing cooperatives in the Bekaa valley are highly linked to their local environment for procurement of raw agricultural material whereas greatly depend on the capital's urban market for sales (Fig. 2). Results show that over $80 \%$ of cooperatives are directly dependent on local farmers within the district level, and almost $60 \%$ stated that more than half of their turnover originates from Beirut; of those, half reach up to threequarters of urban turnover. Cooperatives mostly rely on seasonal events and food exhibitions to access urban consumers and only $30 \%$ reported marketing to retailers and specialty food shops. However, it is not clear if these cooperatives directly reach such outlets or depend on mediators with which around $40 \%$ of cooperatives reporting having links. Comparable geographic dependence is noted in other cooperatives of developing countries such as in Ethiopia. Although not all processes are performed by the same cooperative as in Lebanon, the Ada'a dairy cooperative for example has been contributing to an informal organization of rural-urban linkages by distributing production, processing and marketing throughout diverse areas and actors (Tegegne et al. 2007). This strategy is being called for to recognize its benefit for both rural and urban scales. In that regards, a difference between European and American models of cooperatives is denoted. Although the American dairy cooperatives for example are as strong as their European counterparts in the first production stages, only that they contrarily sell their productions to processing facilities rather than conducting these procedures themselves. A weakened vertical integration in the value chain could equally describe the Bekaa valley's food cooperatives. Although evidence show their attempts to tackle downstream marketing, upstream provisions remain dependent on individual farmers rather than handling their production themselves or their procurement from other agricultural cooperatives. However, access to markets remains generally difficult for food cooperatives. Although cooperatives seem to voice their desire to building foreign links and increase export (Abou-Habib et al. 2013b), market access is found to depend on several internal factors of cooperatives as much as external. As such, only 11 of the 40 food cooperatives in the Bekaa own proper means of transportation such as cooled or noncooled vans which restricts easy access to consumers and retailers. Additionally, almost $75 \%$ of 

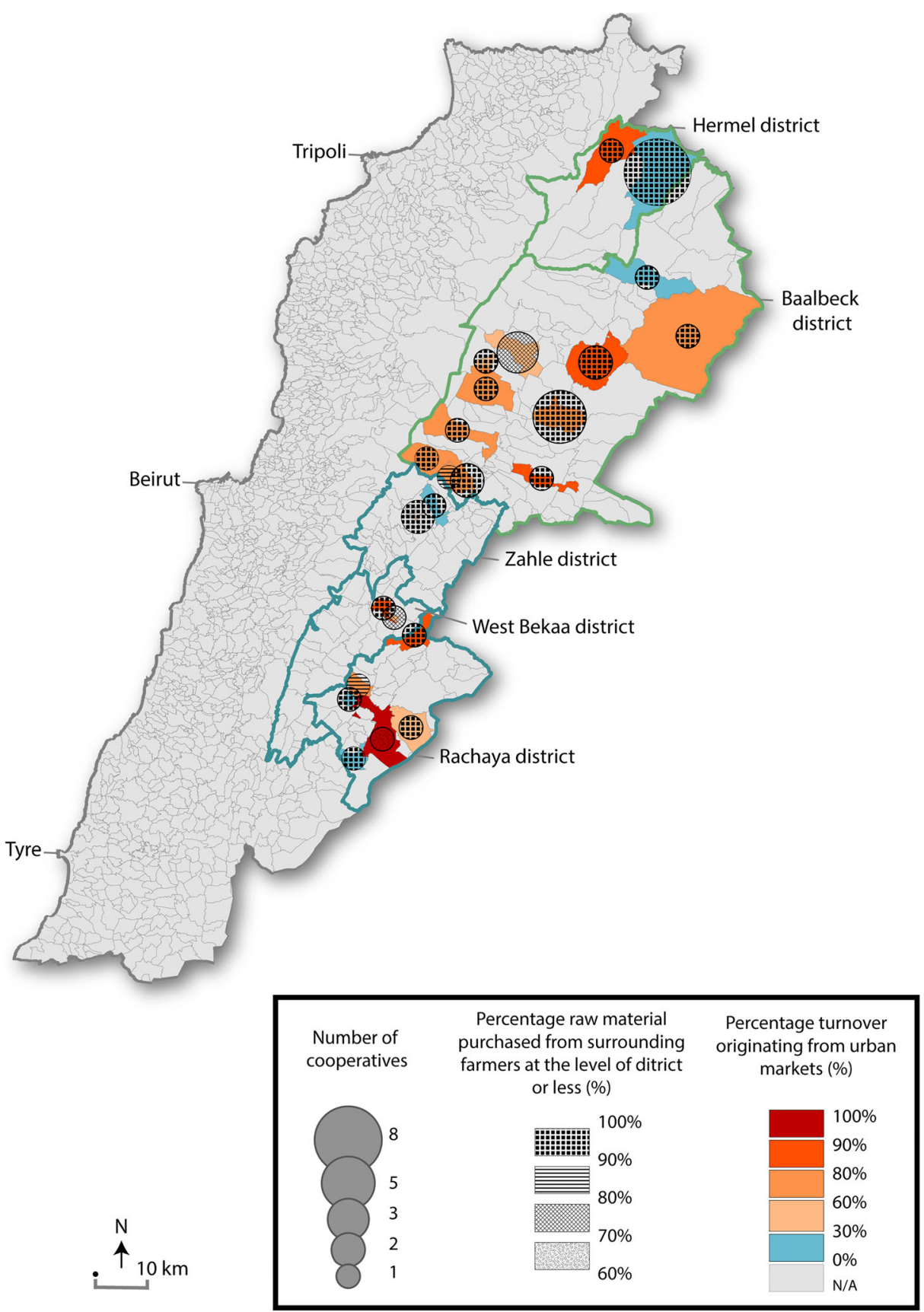

Fig. 2 Spatial distribution of food cooperatives in the Bekaa valley, Lebanon (Baalbeck-Hermel governorate in green and Bekaa governorate in Blue) coupled with the percentage of raw material originating from surrounding farmers at the district level, and the percentage turnover originating from the urban market of the capital Beirut. Source: Jalkh R., 2020, ART-DEV, UM3 
cooperatives do not appear to have proper labels. These scored less than 5 over 10 in their conformity to labeling requirements with $35 \%$ not even owning any labels. Major nonconformities of these cooperatives included handwritten label templates and missing important information such as ingredients, nutrition facts, production/expiry dates and contact information. Cooperatives that did have higher scores were correlated with high urban transactions and sales to intermediaries such as other marketing cooperatives or through nongovernmental organizations (NGO) support. Nonetheless, it should be noted that a large portion of such intermediaries in Lebanon collect end products from different cooperatives and dispatch into the market using their own collective branding. Indeed, $35 \%$ of cooperatives reported selling parts of their production under the private label of other intermediaries. Percentages varied between a minimum of $10 \%$ of production and a maximum of $70 \%$. More investigation is needed in that area to clearly describe the mechanisms, market linkages and external networking of cooperative work in Lebanon as well as dynamics and quality of production. The latter plays a major role in creating a standard quality of products which in turn could affect the market's trust, especially when food cooperatives were reported to vary in the extent of their equipping and setups (ILO 2018).

Extensive aid has been evidently received by food cooperatives in the Bekaa valley mainly by NGOs and on a much lower extent by the state. $65 \%$ of interviewed cooperatives acknowledged receiving support from NGOs compared to $28 \%$ from the state, mostly in the form of equipment and capacity building. The same is similarly reported for cooperatives generally (ILO 2018). On one hand, these forms of support were reported to have developed the production quality of certain cooperatives and their ability to meet local and export standards (ILO 2018). On the other hand, such findings could reinforce statements describing a state of dependency of cooperatives in Lebanon (Esim and Omeira 2009) which would threaten their objectives and sustainability. Such concerns were most recently voiced by McKinsey \& Company (2018) in their report which comments that cooperatives greatly focus on obtaining funds as well as facilitated local sales through the state and international donor support. Further relevant results showed that over half of food cooperatives in the Bekaa valley receive regular support on an annual basis from which $26 \%$ receive such support more frequently, up to 3 to 5 times annually. These cooperatives did register high urban sales especially through outlets related to private labels of intermediaries. This raises the question whether such donor projects are to be credited for bridging cooperatives with the market and whether sustainable linkages are successfully being established.

Although food cooperatives in the Bekaa valley and Lebanon are dwarfed when compared to private industries and are labeled as donor-dependent, their possible contribution to local development remains viable. In fact, the cooperative movement at a global scale is reported to similarly face increasing competition from larger food industries (Nilsson and van Dijk 1997). Conversely, this same author notes that cooperatives could generally benefit from a "market power" being the "satisfaction of consumer preferences for domestic, locally produced food, and here the cooperatives are most often strong", with a similar statement resonated by (Ponte 2016). These observations fit the Lebanese context especially since (Tueni et al. 2015) prove how Lebanese citizens retain high importance for traditional foods, consuming on average two traditional dishes per day. Since mouneh products are well integrated in the Lebanese cuisine, it could be therefore assumed that rural and urban populations alike have a high affinity towards traditional food products. Both rural and urban consumers are concerned because Lebanon witnessed significant internal migration during and after its years of conflict. A large population concentrated in 
the capital Beirut (Esim and Omeira 2009) with smaller and intermediary cities' populations more than quadrupling between 1980 and 2016 (Thapa and Murayama 2008; Lerner et al. 2013). Despite limited research on consumer behavior, it can be therefore suspected that this migration made Beirut and its suburbs a breeding ground for traditional consumption habits. With Lebanon's small surface area of $10,452 \mathrm{~km}^{2}$, it is also likely that citizens retain a link to their proximal villages of origin and thus hold a potential customer loyalty. An additional opportunity also brews with the massive Lebanese diaspora which is estimated at more than triple the number of national residents (Skulte-Ouaiss and Tabar 2015), even though export of food products remains low at less than $4 \%$ of total export value as per McKinsey \& Company (2018). The popular report even positions diaspora inflows as a key driver for the economy. As it mentions that $25 \%$ of all banking deposits originate from that inflow, the diaspora however becomes even more significant than the country's productive sectors themselves.

Today, with Lebanon's quick changing context and concocssion of economic, social and health crises, cooperatives generally and food cooperatives specifically have the potential to fill different gaps in the country. These could most notably include poverty, gender and food security. This is why a call to increase local production and return to the traditional stocking of pantry foods can be even noticed in media outlets and journals. Food cooperatives can therefore enter the development cycle as typical territorial actors being operational within local municipal borders. Their principles relevantly call for a collective benefit of members by sharing risks and resources, generating income, enhancing livelihoods and maintaining democratic governance. Being located in a distinctively agricultural setting, a suitable entryway could entail valorizing their artisanal practices in producing traditional mouneh foods using local sources of fresh produce. This could reflect benefit on the upstream and downstream of value chains given the restrictions in importation as a result of the economic contraction and current disruptions of global food supply from COVID-19. When considering food as a carrier of culture (Jones 2017), the additional role of food cooperatives as protectors of heritage becomes even more apparent. Although the culture of mouneh is common across Lebanon and presents similarities with neighboring countries of the Levant, the Bekaa valley appears to present its own set of characteristics which resonate on agricultural produce and their final processed products. "Almost every resident is a farmer" (Bou-Antoun 2014) is an observation that also adds to the Bekaa valley a social factor to its existing agriculture atmosphere. Nonetheless, it remains imperative to introduce a differentiation scheme of such a cultural resource from commercial analogues; a necessity already voiced by other researchers (Abou-Habib et al. 2013a). That could be embodied by national standards built to orchestrate concerned players across value chains in meeting specific norms and its communication to end consumers via certification and strategic branding. This differentiation approach may yet play a significant role in the urban capital where a large portion of mouneh foods is already traded.

\section{Conclusion}

The reputation of the Lebanese cuisine at a global level indicates the culinary richness of this small Mediterranean country. Main components in that cuisine entail different traditional products that hold a cultural significance, called mouneh. Although the practice still but hardly exists, mouneh foods were historically produced by households mainly to preserve summer produce and extend their shelf-life to ensure food security needs. Today, rural food processing 
cooperatives are progressively participating in the production of such traditional foods. However, they still face a market strongly dominated by similar mass-produced products, a lack of proper state control and no official protection. Due to their cultural importance, such food products may be a key stimulus to elevate the status of rural cooperatives. Food processing cooperatives could specifically intervene not only socially, in alleviating poverty and enhancing livelihoods, but also in mitigating risks of food insecurity through the mobilization and shelf-life extension of local fresh produce. These are much needed in times when Lebanon is facing multifaceted crises related to economic downfall exacerbated by a recent massive explosion in its capital and a global pandemic. The Bekaa valley could be considered a suitable starting point mainly due to its important agricultural position and its geoclimatic conditions. Because the latter are distinct than those of the remainder of the country, they would expectedly reflect on the quality of fresh produce and end products. This article therefore constitutes a first analysis of site evidence which retraces overall interactions between mouneh foods and processing cooperatives within their territory. The study shows that food cooperatives in the Bekaa valley remain small-scale with less than 20 members on average; a fact which could presumably be echoed to food cooperatives in Lebanon generally. Production size varies mostly between 1 and 7 tons and rarely surpasses 15 tons, but those figures do not represent the full capacity of food cooperatives. Given those facts, several inputs bring additional evidence of how these territorial actors could fuel and strengthen their latent impact. These include a high engagement of women, solid reputation as authentic producers, reliance on local farmers, important dispatch to the urban capital and evident support by donors. Because Lebanon has a small overall surface area, a few sources indicate that a largely rural population is currently residing in or around the capital following internal migration due to previous conflict or seek of employment. This further emphasizes the market potential. If properly constructed, framed and managed, a system based on added value could therefore place cooperatives at a strategic position. Such strategies could potentially encourage cooperatives to reorganize in concrete networks to scale up production, highlight product quality and benefit on a collective level. An increase in their respective activities would therefore expectedly reflect on their direct and indirect environments, and equally on their contribution to sustainable development goals and even ambitious national attempts at food autonomy. A probable adaptation of endogenous development approaches in Lebanon and the Bekaa valley could therefore consider cooperatives as possible players. Yet, differentiating such products from similar commercial counterparts remains pivotal. Because certain cooperatives registered links with intermediaries and NGOs, it would also be interesting to further explore their mechanisms, impact and sustainability. Nevertheless, several internal and external challenges are still facing cooperatives. These primarily include, but are not limited to, an aging cooperative and farming population with low attraction to the youth, varying structures and quality of production, challenging access to markets, inexistent national specifications, institutional considerations, and fragile foundation and access to reliable data.

Availability of Data and Material Not applicable.

Code Availability Not applicable.

\section{Compliance with Ethical Standards}

Conflict of Interest On behalf of all authors, the corresponding author states that there is no conflict of interest. 


\section{References}

Abou-Habib, Lina, Omar Traboulsi, Aziza Khalidi, and Habbouba Aoun. 2013a. Factors of market access success for traditional food industry in Lebanon: Some themes pertinent to rural women's cooperatives. In Gender Research in Natural Resource Management ;131-131. Routledge.

Abou-Habib, Lina, Omar Traboulsi, Aziza Khalidi, and Habbouba Aoun. 2013b. Access of rural women's cooperatives to markets in Lebanon: Barriers, enablers and options for action. In Gender Research in Natural Resource Management :111-130. Routledge.

Abu Ghyda, Thana. 2007. Article on inventory products potentially eligible for PDOs and PGIs in Lebanon. Lebanon: TAG/FBR.

Bagchi, Kanak Kanti, and Ganesh Prasad Gautam. 2019. Cooperatives as a means of fostering integrated and sustainable development. In Presented at UNTFSSE International Conference in Geneva, 25:26.

Bosworth, Gary, Ivan Annibal, Terry Carroll, Liz Price, Jessica Sellick, and John Shepherd. 2016. Empowering local action through neo-endogenous development; the case of LEADER in England. Sociol Ruralis 56: $427-449$.

Bou-Antoun, Layal. 2014. Food-processing industry as a basis for community dynamics and local socioeconomic development. In Mediterranean Interdisciplinary Forum on Social Sciences and Humanities, MIFS. Beirut, Lebanon.

Chalak, Ali, Alexandra Irani, Jad Chaaban, Issam Bashour, Karin Seyfert, Kaitlyn Smoot, and Gumataw Kifle Abebe. 2017. Farmers' willingness to adopt conservation agriculture: New evidence from Lebanon. Environmental Management 60: 693-704. https://doi.org/10.1007/s00267-017-0904-6.

Challita, Claude. 2010. Quelles valorisations de produits agro-alimentaires typiques libananais? Institut des Sciences et Industries du. AgroParisTech: Vivant et de l'Environnement.

Darwish, Talal. 2013. Soil resources of Lebanon. In Soil Resources of Mediterranean and Caucasus Countries. Extension of the European Soil Database, ed. Yusuf Yigini, Panos Panagos, and Luca Montanarella, 150. Luxembourg: Joint Research Centre of the European Commission. https://doi.org/10.2788/91322.

Delgado-Serrano, María del Mar, Mateo Ambrosio-Albalá, and Francisco Amador. 2015. Exploring prospective structural analysis to assess the relevance of rural territorial development in Spain and Nicaragua. Cuad. Desarro. Rural. 12: 35-56.

Dixon, Ruth B. 1982. Women in agriculture: Counting the labor force in developing countries. Population and Development Review. JSTOR: 539-566.

El Laithy, Heba, Khalid Abu-Ismail, and Kamal Hamdan. 2008. Poverty, growth and income distribution in Lebanon. International Policy Centre for Inclusive Growth.

El Tabch, Lana. 2018. The Lebanese Economy in 2017. Report for the chamber of commerce, industry and agriculture of Beirut and Mount Lebanon. Center for Economic Research.

ESCWA. 2016. Strategic review of food and nutrition security in Lebanon.

Esim, Simel, and Mansour Omeira. 2009. Rural women producers and cooperatives in conflicts settings in the Arab states. In In FAO-IFAD-ILO Workshop on Gaps, trends and current research in gender dimensions of agricultural and rural employment: differentiated pathways out of poverty. Vol. Draft: Rome, Italy.

Galdeano-Gómez, Emilio, José A. Aznar-Sánchez, and Juan C. Pérez-Mesa. 2011. The complexity of theories on rural development in Europe: An analysis of the paradigmatic case of Almería (South-East Spain). Sociol Ruralis 51: 54-78.

Grace, Dave. 2014. Measuring the size and scope of the cooperative economy: Results of the 2014. Global Census on Co-operatives. United Nation's Secretariat Department of Economic and Social Affairs Division for Social Policy and Development.

Habib, Rima R., and Fadi A. Fathallah. 2012. Migrant women farm workers in the occupational health literature. Work 41. IOS press: 4356-4362.

IDAL. 2020. Agri-food industry. 2020 Factbook. Investment Development Authority of Lebanon.

ILO. 2018. The cooperative sector in Lebanon. What role? What future?

Jones, Bradley M. 2017. Edible identities: Food as cultural heritage. Food and Foodways 25: $247-249$. https://doi.org/10.1080/07409710.2017.1301153.

Lamine, Claire, Henk Renting, Rossi Adanella, J.S.C. Wiskerke, and Gianluca Brunori. 2012. Agri-food systems and territorial development: Innovations, new dynamics and changing governance mechanisms. In Farming systems research into the 21st century: The new dynamic, ed. Ika Darnhofer, David Gibbon, and Benoit Dedieu, 229-256. Dordrecht: Springer Netherlands. https://doi.org/10.1007/978-94-007-4503-2_11.

Lateef, A.S. 2007. Geological history of the Bekaa Valley. In In Second International Conference on the Geology of the Tethys, Cairo University, 391-402.

Lebanese Ministry of Agriculture. 2014. Ministry of Agriculture Strategy 2015-2019. Lebanon: Lebanese Ministry of Agriculture. 
Lerner, Amy M., Hallie Eakin, and Stuart Sweeney. 2013. Understanding peri-urban maize production through an examination of household livelihoods in the Toluca metropolitan area, Mexico. Journal of Rural Studies 30: $52-63$.

Massaad, Barbara Abdeni. 2017. Mouneh: Preserving foods for the Lebanese pantry. Northampton, Massachusetts: Interlink Publishing Group, Incorporated.

McKinsey \& Company. 2018. Lebanon Economic Vision. Full: Report.

Ministry of Economy and Trade. 2008. An ABC guide on EU food packaging and labeling requirements. QUALEB Quality Programme.

Nilsson, Jerker, and Gert van Dijk. 1997. Strategies and structures in the Agro-food industries.

Okem, Andrew Emmanuel. 2016. Theoretical and empirical studies on Cooperatives: Lessons for Cooperatives in South Africa. Springer. https://doi.org/10.1007/978-3-319-34216-0.

Pecqueur, Bernard. 2013. Territorial development. A new approach to development processes for the economies of the developing countries. R. Inter. Interdisc. INTERthesis 10: 25. https://doi.org/10.5007/1807-1384.2013 v10n2p8.

Petrick, Martin. 2011. Halting the rural race to the bottom: An evolutionary model of rural development to analyse neo-endogenous policies in the EU. In EAAE 2011 Congress Change and Uncertainty. Challenges for Agriculture, Food and Natural Resources. ETH Zurich, Zurich, Switzerland.

Pomeranz, Yeshajahu. 1989. Wheat is unique: Structure, composition, processing, end-use properties, and products. In Wheat Industry Utilization Conference, San Diego, Calif.(USA), 1988. American Association of Cereal Chemists.

Ponte, Stefano. 2016. Convention theory in the Anglophone agro-food literature: Past, present and future. Journal of Rural Studies 44: 12-23.

Quan, Julian, and Valerie Nelson. 2005. Territory and rural development: Concepts, methods and approaches. Vol. 2. Land Access and Participatory Territorial Development. Land and Territory Research Paper. Natural Resources Institute.

Ray, Christopher. 2001. Culture economies. Newcastle: Centre for Rural Economy.

Skulte-Ouaiss, Jennifer, and Paul Tabar. 2015. Strong in their weakness or weak in their strength? The case of lebanese diaspora engagement with Lebanon. Immigrants \& Minorities 33. Routledge: 141-164. https:/doi. org/10.1080/02619288.2013.877347

Smith, Stirling. 2014. Promoting cooperatives: An information guide to ILO recommendation no. 193. Geneva: ILO.

Stiglitz, Joseph E. 2007. Making globalization work. New York: WW Norton \& Company.

Stöhr, Walter. 1980. Development from below: The bottom-up and periphery-inward development paradigm. IIR-discussion papers, 6. WU Vienna University of Economics and Business, Vienna.

Swyngedouw, Erik. 2004. Globalisation or 'glocalisation'? Networks, territories and rescaling. Cambridge Review of International Affairs 17: 25-48. https://doi.org/10.1080/0955757042000203632.

Tegegne, Azage, Berhanu Gebremedihin, Dirk Hoekstra, and Nigatu Alemayehu. 2007. Rural urban linkage in market-oriented dairy development in Ethiopia: Lessons from the Ada'a dairy cooperative. Fostering new development pathways: harnessing rural-urban linkages (RUL) to reduce poverty and improve environment in the highlands of Ethiopia: 29-30.

Thapa, Rajesh Bahadur, and Yuji Murayama. 2008. Land evaluation for peri-urban agriculture using analytical hierarchical process and geographic information system techniques: A case study of Hanoi. Land Use Policy 25: $225-239$.

The Government of Lebanon and the United Nations. 2019. Lebanon Crisis Response Plan 2017-2020. 2019 update. The Government of Lebanon and the United Nations.

Torre, André, and Frédéric Wallet. 2014. Introduction: The role of proximity relations in regional and territorial development processes. In Regional development and proximity relations., ed. André Torre and Frédéric Wallet. London: Edward Elgar publishing.

Tueni, Maya, Afifee Mounayar, and Ines Birlouez-Aragon. 2015. Study for assessment of traditional food intake in Lebanon. In Annals of Nutrition and Metabolism, 67:145-146. Karger Allschwilerstrasse 10, CH-4009 Basel, Switzerland.

UNDP. 2020. Gendered value chains study: Barriers and opportunities.

UNOCHA. 2020. Lebanon flash appeal.

Wanyama, Fredrick O. 2016. Cooperatives and the sustainable development goals a contribution to the post-2015 development debate. ILO.

World Bank. 2018. The role of food and agriculture for job creation and poverty reduction in Jordan and Lebanon. Agricultural Sector Note (P166455).

World Economic Forum. 2020. Global Gender Gap Report 2020.

Youssef, Jamile. 2020. Economic overview Lebanon. Available at SSRN 3519485. 
Zurayk, Rami, and Thana Abu Ghyda. 2009. The Lebanese terroir: A challenge of quality. In Localizing products: a sustainable approach for natural and cultural diversity in the South? Paris.

Zurayk, Rami, and Sami Abdul Rahman. 2008. From 'Akkār to 'Amel: Lebanon's slow food trail: Places, products and producers from Lebanon. Slow Food Beirut.

Publisher's Note Springer Nature remains neutral with regard to jurisdictional claims in published maps and institutional affiliations.

\section{Affiliations}

\section{Rita Jalkh ${ }^{1,2} \cdot$ Marc Dedeire $^{1} \cdot$ Melanie Requier Desjardins ${ }^{2}$}

1 University of Montpellier 3 Paul Valery, UMR 5281 ART-Dev, 34199 Route de Mende, Montpellier Cedex 5, France

2 Mediterranean Agronomic Institute of Montpellier, 3141 Route de Mende, Montpellier Cedex 5, France 